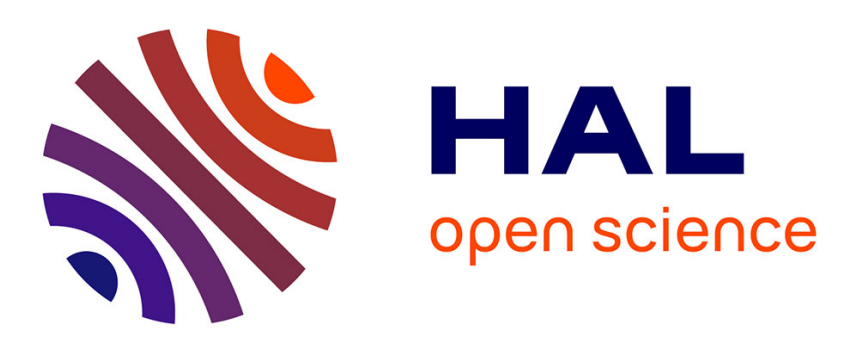

\title{
Photorefractive effect in (001)-cut GaAs at short pulse excitation
}

Kestutis Jarašiunas, L. Bastiene, Philippe Delaye, Gérald Roosen

\section{To cite this version:}

Kestutis Jarašiunas, L. Bastiene, Philippe Delaye, Gérald Roosen. Photorefractive effect in (001)-cut GaAs at short pulse excitation. Optical Materials, 1995, 4, pp.227-232. 10.1016/0925-3467(94)000646. hal-00686033

\section{HAL Id: hal-00686033 \\ https://hal-iogs.archives-ouvertes.fr/hal-00686033}

Submitted on 6 Apr 2012

HAL is a multi-disciplinary open access archive for the deposit and dissemination of scientific research documents, whether they are published or not. The documents may come from teaching and research institutions in France or abroad, or from public or private research centers.
L'archive ouverte pluridisciplinaire HAL, est destinée au dépôt et à la diffusion de documents scientifiques de niveau recherche, publiés ou non, émanant des établissements d'enseignement et de recherche français ou étrangers, des laboratoires publics ou privés. 


\title{
PHOTOREFRACTIVE EFFECT IN (001)-CUT GaAs AT SHORT PULSE
}

\section{EXCITATION}

\author{
K.Jarasiunas, L.Bastiene, P.Delaye ${ }^{\circ}$, G.Roosen ${ }^{\circ}$ \\ Institute of Material Science and Applied Research, Vilnius University, Sauletekio ave 9-3, \\ 2054 Vilnius, Lithuania. \\ •Institut d'Optique Théorique et Appliquée, Unité de Recherche Associée 14 au Centre \\ National de la Recherche Scientifique, Bât.503, Centre Scientifique d'Orsay, B.P. 147, \\ 91403 Orsay Cedex. Fax +33-1-69413192 E-mail: Gerald.Roosen@iota.u-psud.fr
}

\begin{abstract}
We present experimental studies of photorefractive effect in non-photorefractive orientations of LEC-grown GaAs crystals. Picosecond DFWM experiments, carried out in different samples, show that forbidden photorefractive signal correlates well with dislocation density and confirms hypothesis that the effect arises from strain fields around growthdefects.
\end{abstract}

\section{Introduction}

Light diffraction on transient gratings is a powerful technique to study dynamics of photoelectrical properties of semiconductors via different mechanisms of light-induced optical nonlinearities. At short pulse excitation some interacting mechanisms of refractive index modulation may take place simultaneously [1-7]. The proper selection of experimental conditions (as excitation level, crystal orientation, temporal or spectral domain, temperature), permits to separate the coexisting mechanisms.

In photorefractive semiconductors, two mechanisms of refractive index modulation coexist at short pulse excitation : an intrinsic local one, based on nonequilibrium carriers, and a second one, that is non local, of photorefractive origin, based on internal space-charge (SC) electric fields due to fast carrier redistribution. Free carrier (FC) nonlinearity is isotropic and 
for frequencies far from the direct band-gap is described by Drude-Lorentz model [8]:

$$
\Delta \mathrm{n}=-\left(\mathrm{e}^{2} / 2 \mathrm{n}_{0} \omega^{2} \varepsilon_{0}\right)\left(\Delta \mathrm{N} / \mathrm{m}_{\mathrm{e}}+\Delta \mathrm{P} / \mathrm{m}_{\mathrm{p}}\right)
$$

where $\Delta \mathrm{N}, \Delta \mathrm{P}$ are the nonequilibrium carrier concentrations, $\mathrm{m}_{\mathrm{e}, \mathrm{p}}$ are their effective masses, and $\omega$ is the laser frequency. For photorefractive (PR) mechanism, index modulation seen by a probe beam depends on its polarization and on the orientation of the crystal principal axes with respect to grating vector $\mathrm{K}_{\mathrm{g}}$ :

$$
\Delta \mathrm{n}=-\mathrm{n}_{0}^{3} \mathrm{r}_{\mathrm{eff}} \mathrm{E}_{\mathrm{sc}} / 2
$$

where $r_{\text {eff }}=e_{i}\left[R k_{g}\right] e_{d}$ is the effective electro-optic coefficient, $R$ is electro-optic tensor, $e_{i, d}$ are the polarization vectors of incident and diffracted waves, $\mathrm{k}_{\mathrm{g}}$ is the unit grating vector, $\mathrm{E}_{\mathrm{sc}}$ is the space charge electric field. For crystals with $\overline{4} 3 \mathrm{~m}$ symmetry, anisotropy of light diffraction on PR gratings is well known and analyzed in [9]. In the common photorefractive crystal cut (i.e. with faces along crystallographic directions [110], [ 110$]$, and [001]) and for $\mathrm{K}_{\mathrm{g}}$ along [110], a rotation of polarization of diffracted beam takes place (phenomenon known as anisotropic diffraction). This peculiarity was used to separate contribution of PR grating from the much stronger but isotropic FC grating contribution at picosecond pulse excitation [10-12]. Such an anisotropic diffraction process does not exist for $\mathrm{K}_{\mathrm{g}}$ along [001].

Nevertheless, a strong diffracted signal with rotated polarization was recently observed in LEC-grown semi-insulating GaAs for grating orientation $\mathrm{Kg} / /[001]$ [12], while no anisotropic diffraction was seen in vanadium doped CdTe in the same conditions. We attributed this unexpected signal to internal strains and electric fields around charged dislocations : the distorsions of the lattice may lead to extremely large local potentials [13] and extend over 5-10 Debye lengths in GaAs [14]. That may break the crystal symmetry and create non-zero components of electro-optic tensor.

In this paper we extend our studies on the origin of this novel effect which we suppose to be dependent on dislocation density. The samples of LEC-grown GaAs with different dislocation densities and specific non-photorefractive orientations have been investigated. The analysis of carrier transport and SC field formation at picosecond excitation allows us to find criteria in diffracted characteristics, when SC field between ionized donors and electrons dominates over the Dember field. 


\section{Samples and techniques}

PR and FC picosecond gratings have been studied in four LEC- grown GaAs crystals, differently cut and containing various dislocation densities. The first sample (\#1), an undoped semi-insulating GaAs crystal $\left(\rho=5.10^{7} \Omega . \mathrm{cm}\right.$, dislocation density $\mathrm{N}_{\mathrm{D}}=10^{5} \mathrm{~cm}^{-2}$, thickness $\mathrm{d}=1.5 \mathrm{~mm}$ ) was cut in a typical photorefractive way. Transient gratings in this sample have been studied in two orientations $(\mathrm{Kg} / /[110]$ and $\mathrm{Kg} / /[001])$ with light beams propagating along direction [ $\overline{1} 10]$. In both cases, p-diffracted component of s-polarized probe beam is attributed to PR grating contribution while the non-rotated component of $\mathrm{p}$ polarized probe gives the strength and decay of FC grating.

The following three samples have been cut along face (001) from three different GaAs crystals. Sample \#2 was a semi-insulating In-alloyed wafer $\left(\rho=5.10^{6} \Omega . c m\right.$, $\mathrm{N}_{\mathrm{D}}=3.10^{4} \mathrm{~cm}^{-2}$ in the central part of the wafer,and $\mathrm{d}=1.1 \mathrm{~mm}$ ) ; the boule was moderately indium-doped to reduce dislocation density [15]. Samples \#3 and \#4 were commercial (001)grown GaAs wafers : a semi-insulating one $\left(\rho=5.10^{7}-10^{8} \Omega . \mathrm{cm}, \mathrm{N}_{\mathrm{D}}=4.10^{4} \mathrm{~cm}^{-2}, \mathrm{~d}=0.5 \mathrm{~mm}\right)$ and a heavily doped by silicon up to the free electron concentration $\mathrm{N}_{0}=10^{18} \mathrm{~cm}^{-3}\left(\rho=10^{-}\right.$ $\left.{ }^{4} \Omega . \mathrm{cm}, \mathrm{N}_{\mathrm{D}}=2.10^{3} \mathrm{~cm}^{-2}, \mathrm{~d}=0.5 \mathrm{~mm}\right)$. Dislocation density in the latter sample is rather low because of strong doping by shallow impurity [15].

Degenerate four wave mixing (DFWM) experiments were performed by using the set-up which is described in our previous work [12]. We use a YAG-laser emitting a 28-ps duration pulse with energy up to $10 \mathrm{~mJ} . \mathrm{cm}^{-2}$ at $1.06 \mu \mathrm{m}$ wavelength. Two s-polarized beams of equal intensity record a grating with period $\Lambda=1.8 \mu \mathrm{m}$. Grating decay was monitored by delayed p- or s-polarized probe beam and polarization sensitive read-out system [10-12]. Exposure and decay characteristics (i.e. dependences of the diffracted beam energy $I_{1}$ vs. excitation energy density $I_{0}$, or $I_{1}$ vs. probe beam delay time $\Delta t$ ) have been measured for coexisting PR and FC gratings in given above orientations of the crystals. Preliminary measurements of light diffraction on FC and PR gratings have been performed by using 10 ns duration pulses and DFWM configuration. 


\section{Carrier and space charge field dynamics}

We carried out analysis of nonequilibrium carrier and SC field dynamics at given experimental situations to find out regimes when role of deep EL2 centers is most pronounced.

At short pulse excitation, electric fields of two origin are created in photorefractive crystals [5,12]: a space charge field $\mathrm{E}_{1}$ between ionized EL2 donors and electrons at monopolar carrier generation, and a Dember field $\mathrm{E}_{2}$ between mobile charges at pure bipolar one. The modelisation of diffraction characteristics at given grating period $\Lambda=1.8 \mu \mathrm{m}$ has shown that the ratio of $E_{1} / E_{2}$ varies with excitation power and time [16]. An indication of an increasing $\mathrm{E}_{2}$ component with excitation is a fast decay time of $\mathrm{FC}$ or PR gratings which reaches its ambipolar limit $\tau_{\mathrm{a}}=1 / \mathrm{K}_{\mathrm{g}}{ }^{2} \mathrm{D}_{\mathrm{a}}=\left(\mathrm{e} / \mathrm{K}_{\mathrm{g}}{ }^{2} \mathrm{kT}\right)\left(\mathrm{N} / \mu_{\mathrm{p}}+\mathrm{P} / \mu_{\mathrm{n}}\right) /(\mathrm{N}+\mathrm{P})=43 \mathrm{ps}$. The transport of holes in $E_{1}$ field will lead to a $\pi$-shifted hole grating and screening of the negative charge of electrons.

The transfer from slow $\mathrm{SC}$ field component $\mathrm{E}_{1}$ to fast one $\mathrm{E}_{2}$ is also revealed in the exposure characteristics as a change in the power law dependence $I_{1}=A I_{0}^{\gamma}$ [12]. For FC gratings, the slope $\gamma=\Delta\left[\log \left(\mathrm{I}_{1}\right)\right] / \Delta\left[\log \left(\mathrm{I}_{0}\right)\right]$ decreases from $\gamma=4-5$ to $\gamma=3$ as found experimentally and numerically $[12,16]$. For PR gratings, the decrease in $\gamma$ value is always more pronounced (from $\gamma=4-5$ to $\gamma=2-2.5$ ). This is because the decrease of FC grating is compensated by a nonlinear increase of carrier concentration due to two-photon absorption of light, while the PR effect, based on carrier transport, depends on grating modulation depth. In addition, screening of $\mathrm{E}_{1}$ by nonequilibrium holes will also lead to lower values of $\gamma$ for PR grating.

All these peculiarities in diffraction characteristics pointed out that in order to reveal the role of dislocations, one must carry out measurements at the possibly lowest excitations, when deep-trap assisted carrier generation still dominates over two-photon absorption of light. Modelisation of carrier and field dynamics by solving system of differential equations [16] and previous experiments in GaAs [12] have indicated that excitation level must be below $5 \mathrm{~mJ} . \mathrm{cm}^{-2}$. In the following, we compare the strength of the diffracted FC and PR 
signals at a fixed value of $\mathrm{I}_{0}=2.5 \mathrm{~mJ} . \mathrm{cm}^{-2}$.

\section{Experimental data}

\subsection{Photorefractive-cut GaAs (sample \#1)}

We compare diffraction characteristics in two different orientations of grating vector $\left(\mathrm{K}_{\mathrm{g}} / /[110]\right.$ and $\left.\mathrm{K}_{\mathrm{g}} / /[001]\right)$ in order to analyze the origin of the observed effect [12].

For $\mathrm{K}_{\mathrm{g}} / /[110]$, we find that $\mathrm{FC}$ grating diffraction characteristics at $\mathrm{I}_{0} \approx 3-4 \mathrm{~mJ} . \mathrm{cm}^{-2}$ are governed by nonequilibrium carriers generated mainly from/via deep traps and, thus, SC field component $\mathrm{E}_{1}$ dominates. Indeed, at low excitation levels $\left(\mathrm{I}_{0}=1-2 \mathrm{~mJ} . \mathrm{cm}^{-2}\right)$ the first decay component is found equal to $\tau_{1}=80$ ps for both FC and PR gratings, what corresponds to hole redistribution in SC field with $\tau_{\mathrm{p}}=1 / \mathrm{K}_{\mathrm{g}} \mu^{*} \mathrm{E}_{1}$ and subsequent screening of SC field (here $\mu^{*}=(\mathrm{N}-\mathrm{P}) /\left(\mathrm{N} / \mu_{\mathrm{p}}+\mathrm{P} / \mu_{\mathrm{n}}\right)$ is drift mobility). In addition, the slope of exposure characteristics $\gamma=4$, measured at the end of excitation beam $(\Delta t=26 \mathrm{ps})$ at low excitations, indicates the channel of deep-trap assisted carrier generation.

At $\mathrm{I}_{0}=2.5 \mathrm{~mJ} . \mathrm{cm}^{-2}$, we find that diffracted signal on PR grating equals to $I_{1 P R}=9-10$ rel.u. and that one on FC grating $I_{1 F C}=600$ rel.u.. The ratio of these signals is approximately $1.6 \pm 0.2 \%$. The diffraction efficiencies (ratios of diffracted over transmitted beam energies) on PR and FC gratings are measured equal to $\eta_{\mathrm{PR}}=9.10^{-6}$ and $\eta_{\mathrm{FC}}=7.10^{-4}$ at given excitation, thus giving a ratio $\eta_{\mathrm{PR}} / \eta_{\mathrm{FC}}=1.3 \%$, which is slightly lower due to a larger absorption of s- than p-polarized probe beam [12].

For $\mathrm{K}_{\mathrm{g}} / /[001]$, we observe a twice stronger p-diffracted component of s-polarized probe beam than in $\mathrm{K}_{\mathrm{g}} / /[110]$ case. A similar increase of diffraction was observed for FC grating also. As above, this peculiarity arises due to stronger absorption of s-polarized beams (writing and probing beams as well). The increased absorption leads to more pronounced increase of diffracted signals due to their nonlinear relationship. Following ref.[17, 18], we attribute this absorption dichroism to charged dislocations which are oriented along [110] [19].

Thus the procedure of normalization of $\mathrm{I}_{1 \mathrm{PR}}$ to $\mathrm{I}_{1 \mathrm{FC}}$ helps to overcome the orientation-dependent absorption coefficient without its absolute measurement and 
corrections of diffracted beam efficiencies. From the values measured $I_{1 P R}=20$ rel.u. and $I_{1 F C}$ $=800$ rel.u. at $2.5 \mathrm{~mJ} . \mathrm{cm}^{-2}$, ratio $\mathrm{I}_{1 \mathrm{PR}} / \mathrm{I}_{1 \mathrm{FC}}=2.3-2.7 \%$ is estimated. The exposure characteristics of PR gratings in both orientations (Fig.1, curves 1,2) indicates the transfer from slow $\left(E_{1}\right)$ to fast $\left(E_{2}\right) S C$ field component.

The temporal features of PR grating decay in both orientations are compared in Fig.2 (curves 1,2). They both reveal the processes of fast charge redistribution with time constants $\tau_{\mathrm{e}}=65$ ps which is an intermediate case between monopolar and bipolar carrier transport. With increasing excitation, drift component is saturated (hole concentration approaches electron one, $\mathrm{N} \approx \mathrm{P}$ ), and both $\mathrm{FC}$ and $\mathrm{PR}$ gratings decay with ambipolar diffusion time.

All these similarities in exposure and temporal features confirm that the physical origin of the diffracted signal observed in orientation $\mathrm{K}_{\mathrm{g}} / /[001]$ is the same as in $\mathrm{K}_{\mathrm{g}} / /[110]$, i.e. of photorefractive origin, despite the fact that equation 2 predicts $r_{e f f}=0$ for anisotropic diffraction.

\subsection{Semi-insulating (001)-cut GaAs (samples \#2,\#3)}

In this set of experiments the studies of PR effect are continued in a nonphotorefractive geometry, i.e. in (001)- cut wafers. Usually to monitor the contribution of PR gratings, wafers are tilted with respect to the plane of incidence [20]. Here, we have normal incidences for recording and probe beams and no PR signal is expected. As we will show, such a signal exists and its magnitude depends on dislocation densities.

Time-resolved measurements of picosecond grating decay reveal that growth-defect density contributes significantly to carrier generation and grating erasure processes (Fig.3). In the area with high defect density, electron generation from donor traps dominates, and the SC electric field is created at excitations as low as $1 \mathrm{~mJ} . \mathrm{cm}^{-2}$. The field opposes the initial fast FC grating decay $\tau_{\mathrm{e} 1}=75-80 \mathrm{ps}$, and the grating finally decays by recombination with $\tau_{\mathrm{e} 2}=\tau_{\mathrm{R}}=1.6 \mathrm{~ns}$. If defect density is low, the bipolar carrier generation dominates, and FC grating decays by ambipolar diffusion (here $\tau_{\mathrm{e}} \approx 45 \mathrm{ps}$ ). For the further studies, the area with the high density of dislocations and deep EL2 donors (in the center of the wafer, where

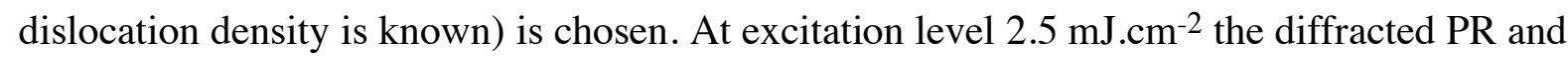
FC signal strengths in this area equal to $I_{1 P R}=5-6$ rel.u. and $I_{1 F C}=1000$ rel.u. ; thus ratio 
$\mathrm{S}=\mathrm{I}_{1 \mathrm{PR}} / \mathrm{I}_{1 \mathrm{FC}}$ is $0.5-0.6 \%$.

Exposure characteristics of PR grating in sample \#3, measured at $\Delta \mathrm{t}=26 \mathrm{ps}$ (see Fig.1, curve 3), shows the slope $\gamma=4.8$ at low excitations $\left(I_{0}<4 \mathrm{~mJ} . \mathrm{cm}^{-2}\right)$ and its decrease to lower value $\gamma \approx 2.4$ at higher excitations. At $\mathrm{I}_{0}=2.5 \mathrm{~mJ} . \mathrm{cm}^{-2}$, ratio $\mathrm{S}=\mathrm{I}_{1 \mathrm{PR}} / \mathrm{I}_{1 \mathrm{FC}}=0.8-1 \%$ is estimated.

\subsection{Heavily doped GaAs (sample \#4)}

In heavily doped GaAs we also observe a p-diffracted component of a s-polarized probe beam, but the diffracted signal is smaller than in semi-insulating samples. Its origin is studied via FC and PR grating decay dynamics and exposure characteristics.

In FC grating (Fig.4), both diffusive process (varying with excitation from $\tau_{1 \text { low }}=170 \mathrm{ps}$ at $2.2 \mathrm{~mJ} . \mathrm{cm}^{-2}$ to $\tau_{1 \mathrm{high}}=100 \mathrm{ps}$ at $9 \mathrm{~mJ} . \mathrm{cm}^{-2}$ ) and carrier recombination $\left(\tau_{2}=1.4 \mathrm{~ns}\right)$ govern decay. Assuming that in heavily doped n-type crystals, gradients of minor carriers dominate $\left(\mathrm{N}_{0}+\Delta \mathrm{N}>>\Delta \mathrm{P}, \mu_{\mathrm{a}}=\mu_{\mathrm{p}}\right)$, from $\tau_{1 \text { low }}$ we determine the value of hole mobility $\mu_{\mathrm{p}}=190 \mathrm{~cm}^{2} \cdot \mathrm{V}^{-1} \cdot \mathrm{s}^{-1}$. Such a low value of hole mobility is expected due to strong ionized impurity scattering in doped $\mathrm{n}$-GaAs [21]. Using this measured value of $\mu_{\mathrm{p}}$ and the known apriori value of electron mobility $\mu_{\mathrm{e}}=2500 \mathrm{~cm}^{2} \cdot \mathrm{V}^{-1} \cdot \mathrm{s}^{-1}$, we calculate the bipolar mobility $\mu_{\mathrm{a}}=330 \mathrm{~cm}^{2} \cdot \mathrm{V}^{-1} \cdot \mathrm{s}^{-1}$ and find it in good agreement with the measured one at higher excitation (bipolar regime).

Photorefractive grating decay, measured at $\mathrm{I}_{0}>3 \mathrm{~mJ} . \mathrm{cm}^{-2}$, reveal the initial fast decay component with $\tau_{\mathrm{PR}}=100 \mathrm{ps}$ in time interval $60 \mathrm{ps} \leq \Delta \mathrm{t} \leq 400 \mathrm{ps}$ and its slowering with delay time (see Fig.2, curve 4). The latter behaviour is typical for photorefractive crystals at short pulse excitation, when competition of fast and slow SC field components takes place [12, 16]. The additional information concerning the origin of SC electric fields is obtained from the change in slope $\gamma$ of exposure characteristics, observed at $\mathrm{I}_{0}>5 \mathrm{~mJ}_{\mathrm{cm}} \mathrm{cm}^{-2}$ (Fig.1, curve 4). Analysis of temporal and exposure characteristics point out that the origin of SC field component $\mathrm{E}_{1}$ at low excitations is due to hole diffusive transport with mobilities varying from $\mu_{\mathrm{p}}$ to $\mu_{\mathrm{a}}$. This slow process is seen in SC field build-up (Fig.2). In order to estimate the ratio $S=I_{1 P R} / I_{1 F C}$, we make extrapolation of PR grating exposure characteristics to excitation energy $2.5 \mathrm{~mJ} . \mathrm{cm}^{-2}$ and estimate the PR signal $\mathrm{I}_{1 \mathrm{PR}}=1$ rel.u. and $\mathrm{S}=0.3 \%$.

\section{Discussion}


Results are summarized in Fig.5. They clearly show the decrease of PR signal in nonphotorefractive geometry with decreasing dislocation density. The ratio of $\mathrm{I}_{1 \mathrm{PR}} / \mathrm{I}_{1 \mathrm{FC}}$ is proportional to the square of induced changes of refractive index due to electro-optic effect and to free carrier concentration:

$$
\mathrm{S}=\mathrm{I}_{1 \mathrm{PR}} / \mathrm{I}_{1 \mathrm{FC}}=\left(\pi \Delta \mathrm{n}_{\mathrm{PR}} \mathrm{d} / \lambda\right)^{2} /\left(\pi \Delta \mathrm{n}_{\mathrm{FC}} \mathrm{d} / \lambda\right)^{2}=\left(\Delta \mathrm{n}_{\mathrm{PR}} / \Delta \mathrm{n}_{\mathrm{FC}}\right)^{2}
$$

From the descriptions of refractive index modulation (by eqs. 1,2) it follows, that the excitation dependent values are the space charge field $E_{S C}\left(E_{1}\right.$ or $\left.E_{2}\right)$ and $\Delta N$ only. Consequently, we have $S \approx\left(r_{\text {eff }}{ }^{*} E_{S C} / \Delta N\right)^{2}$, where $r_{\text {eff }}{ }^{*}$ is the effective electrooptic coefficient in presence of dislocations.

The experiments have shown that in all samples and orientations used slopes $\gamma$ of PR and FC gratings are the same (as illustrated in Fig.1).This indicates that SC fields and carrier concentrations are coupled and would lead to a constant value of $\mathrm{E}_{\mathrm{SC}} / \Delta \mathrm{N}$ at fixed excitation energy. Thus, the experimentally found variation of $S$ with dislocation density $($ Fig. $5,(\bullet))$ is due to modification of $\mathrm{r}_{\mathrm{eff}}{ }^{*}$. Square root of ratio $\mathrm{S}$ shows a linear dependence (Fig. 5,(o)) which points out that $r_{\text {eff }}{ }^{*}$ linearly increases with dislocation density $: r_{e f f}{ }^{*}=r_{e f f}+a N_{D}$.

\section{Conclusion}

The correlation between anisotropic diffraction and dislocation density strongly supports the hypothesis that dislocations are responsible for PR-effect in (001)-cut GaAs samples. We would like to note, that we do not observe anisotropic diffracted signal on grating oriented along [001] in photorefractive-cut vanadium-doped CdTe crystals, grown by Bridgman technique. Because the latter growth-technique gives very low density of dislocations, this observation also supports our hypothesis that local strains and electric fields at macroscopic defects are at the origin of a non- zero effective electrooptic coefficient. First complementary measurements of dynamic gratings using nanosecond duration laser pulses in LEC-grown GaAs samples also reveal this $90^{\circ}$ rotated photorefractive components of diffracted beams in sample \#1 and \#2. Again its strength varies with density of growth-defects. Other studies have revealed dislocation-initiated longrange piezoelectric effects [19], new energy levels and bands [22], anisotropy of optical absorption [18], and mechanism of charged dislocation scattering [23, 24]. Further studies of 
optical nonlinearities and their dynamics at different wavelengths will allow to reach better understanding of mechanisms involved in dislocation-governed carrier transport and refractive index modulation.

K.J. would like to acknowledge the financial support of Ministere de la Recherche (France) and hospitality of Institut d'Optique (Orsay) during his research stay, and the current support of research activities by ISF long-term grant No.LA9000.

\section{REFERENCES}

[1]. A.Miller, R.J.Manning, P.K.Milsom, D.C.Hutchings, D.W.Crust, and K.Woodbridge, J.Opt.Soc.Amer. B 6 (1989) 567.

[2]. K.Leo, E.O.Gobel, T.C.Damen, J.Shah, S.Schmitt-Rink, W.Shafer, J.Muller, K.Kohler, Phys. Rev. B 44 (1991) 5726.

[3]. L.Jonikas, K.Jarasiunas, J.Vaitkus. Phys. stat. sol. (a). 112 (1989) 375.

[4]. A.A.Said, M.Sheik-Bahae, D.J.Hagan, T.H.Wei, J.Wang, J.Young, E.W.Stryland, J.Opt.Soc.Am.B. 9 (1992) 405.

[5]. A.L.Smirl, G.C.Valley, K.M.Bonhert, T.F.Boggess, IEEE J. Quant. Electr. 24 (1988) 289.

[6]. M.S.Petrovic, A.Suchocki, r.C.Powel, G.Cantwell, J.Aldridge, J.Appl. Phys. 66, (1989) 1359 .

[7]. I.Ruckmann, J.Kornack, J.Kolenda, M.Petrauskas, Y.Ding, B.Smandek, Phys. stat. sol.(b) 170 (1992) 353.

[8]. R.K.Jain and M.B.Klein, "Degenerate Four-Wave Mixing in semiconductors", in Optical Phase Conjugation, ed. R.A.Fisher, N.Y. Acad. Press, 1983, p.307.

[9]. J.C.Fabre, J.M.C.Jonathan, G.Roosen. Opt. Comm. 65 (1988) 257.

[10]. W.A.Schroeder, T.S.Stark, M.D.Dawson, T.F.Bogess, A.L.Smirl, G.C.Valley, Optics Letters 16 (1991) 159.

[11]. K.Jarasiunas, P.Delaye. J.C.Launay, G.Roosen, Opt. Commun., 93 (1992) 59.

[12]. K.Jarasiunas, P.Delaye, G.Roosen, Phys. stat. sol.(b) 175, (1993) 445.

[13]. A.R.Hutson and L.R.Walker, J.Appl.Phys.50, (1979) 6247. 
[14]. K. Shintani. J.Appl.Phys.69, (1991) 8119.

[15]. R.N.Thomas, S.McGuigan, G.W.Eldridge, and D.L.Barret, Proc. IEEE, 76 (1988) 778.

[16]. Ph. Delaye, L.Bastiene, K.Jarasiunas, G.Roosen. Proc. SPIE 2096 (1994) (in press)

[17]. L.I. Stephanovitch and E.P.Feldman. Sov. Phys.Solid State 27 (1985) 725.

[18] D.Vignaud, J.L.Farvacque. J.Appl.Phys.65, (1989) 1261.

[19]. H.Booyens, J.S.Vermaak. J.Appl.Phys.50, (1979) 4302.

[20]. B.Bylsma, D.H.Olson, A.M.Glass Appl. Phys. Lett. 52 (1988) 1083.

[21]. J.R.Lowney, H.S.Bennet, J.Appl. Phys. 69 (1991) 7102.

[22]. J.L.Farvacque and B.Podor, Phys.stat.sol. (b) 167 (1991) 687.

[23]. D.Ferre and J.L.Farvacque, Revue Phys. Appl. 25 (1990) 323.

[24]. J. Vaitkus, V.Kazukauskas, R.Kiliulis, J. Storasta. Inst. Phys. Conf. Ser.136 (1993) 755 


\section{Figure captions}

Fig.1. Exposure characteristics of light diffraction on photorefractive gratings with period $\Lambda=1.8 \mu \mathrm{m}$ in differently cut and oriented GaAs crystals: light propagates along [1 10$]$ axis with $\mathrm{Kg} / /[001]$ (1) or $\mathrm{Kg} / /[110]$ (2); light propagates along [001] axis in semi-insulating undoped (3) and heavily-doped (4) GaAs crystals. Probe beam delay time is $26 \mathrm{ps}$.

Fig.2. Photorefractive grating dynamics at different crystal orientations and excitation levels:

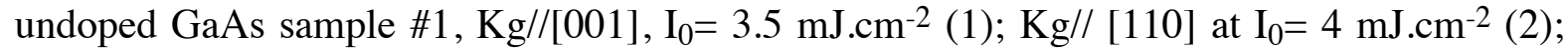
(001)-cut In-alloyed sample, $\mathrm{I}_{0}=2.25 \mathrm{~mJ} . \mathrm{cm}^{-2}(3)$; and heavily doped GaAs at $\mathrm{I}_{0}=4.2 \mathrm{~mJ} . \mathrm{cm}^{-2}$ (4, Signal divided by 10$)$.

Fig.3. Free carrier grating decay in In-alloyed semi-insulating GaAs wafer with different dislocation densities : in the center of the wafer (1) and in the peripherical area (2) ; excitation level for both curves $\left(\mathrm{I}_{0}=1 \mathrm{~mJ} . \mathrm{cm}^{-2}\right)$.

Fig.4. Free carrier grating decay in heavily doped GaAs at $\mathrm{I}_{0}=2.2 \mathrm{~mJ} . \mathrm{cm}^{-2}(1), \mathrm{I}_{0}=4.8 \mathrm{~mJ} . \mathrm{cm}^{-2}$ (2), $\mathrm{I}_{0}=8.5 \mathrm{~mJ} . \mathrm{cm}^{-2}(3)$.

Fig.5. Dependence of ratio $S=I_{1 P R} / I_{1 F C}$ versus dislocation density $N_{D}$ in LEC-grown GaAs crystals $(\bullet)$. The straigth line is a linear regression of the square root of $\mathrm{S}:(\mathrm{o})$. 


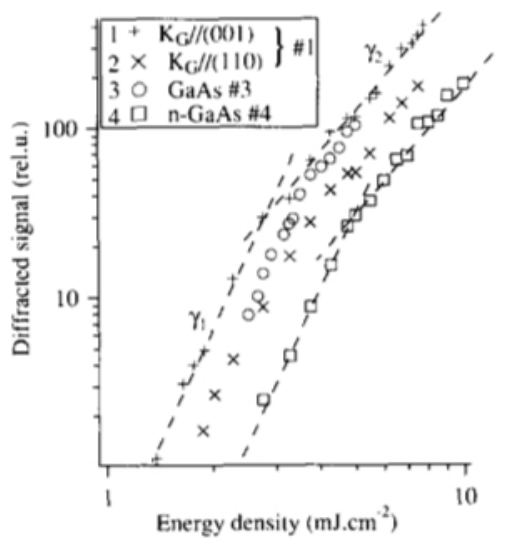

Figure 1

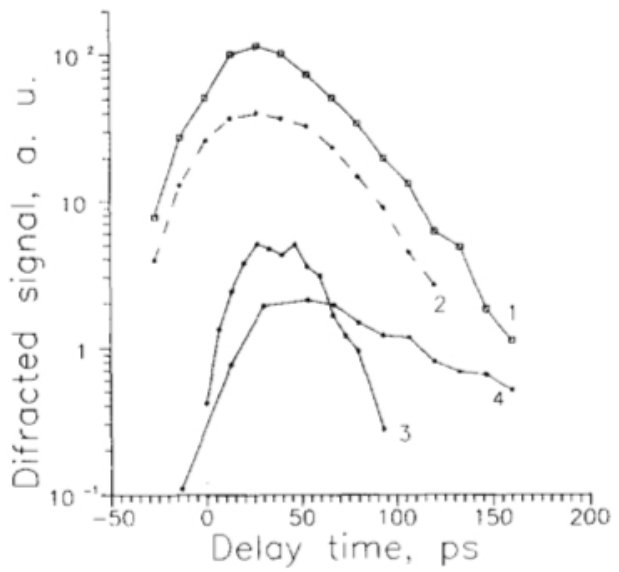

Figure 2

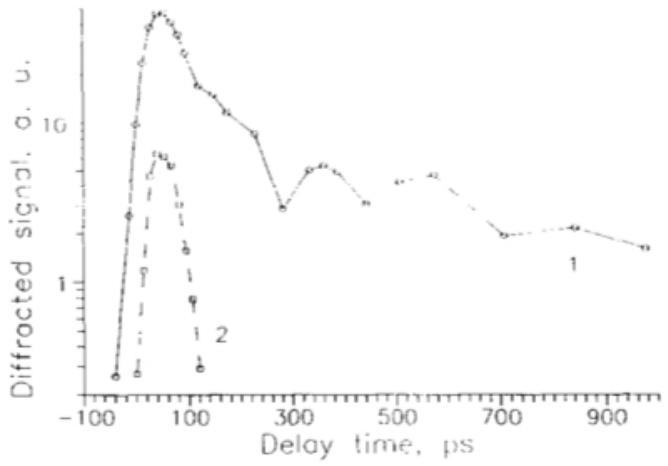

Figure 3

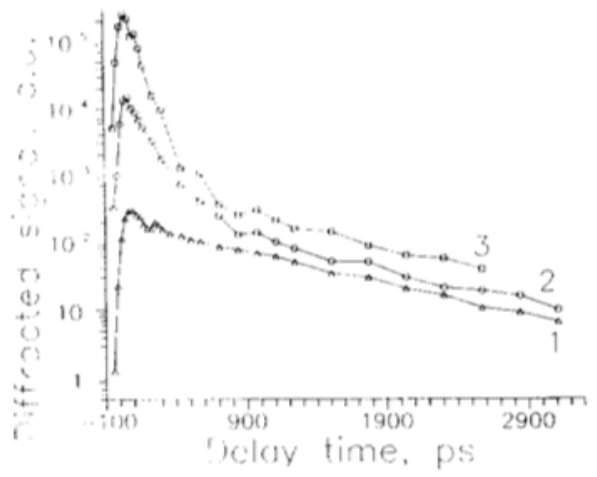

Figure 4 


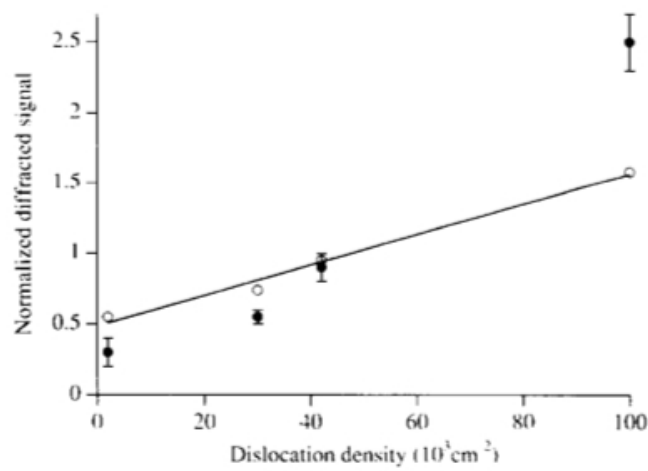

Figure 5 